\title{
Publisher's Note: One-neutron knockout from light neutron-rich nuclei at relativistic energies [Phys. Rev. C 82, 024305 (2010)]
}

C. Rodríguez-Tajes, ${ }^{*}$ H. Álvarez-Pol, T. Aumann, E. Benjamim, J. Benlliure, M. J. G. Borge, M. Caamaño, E. Casarejos, ${ }^{\dagger}$ A. Chatillon, D. Cortina-Gil, K. Eppinger, T. Faestermann, M. Gascón, H. Geissel, R. Gernhäuser, B. Jonson, R. Kanungo, R. Krücken, T. Kurtukian, ${ }^{\dagger}$ K. Larsson, P. Maierbeck, T. Nilsson, C. Nociforo, C. Pascual-Izarra, A. Perea, D. Pérez-Loureiro, A. Prochazka, S. Schwertel, H. Simon, K. Sümmerer, O. Tengblad, H. Weick, M. Winkler, and M. Zhukov

(Received 17 August 2010; published 31 August 2010)

DOI: 10.1103/PhysRevC.82.029910 PACS number(s): 21.10.Gv, 21.10.Pc, 21.60.Cs, 24.50.+g, 99.10.Fg

This paper was published online on 5 August 2010 with some typographical errors in Table I, and some errors in the references. References 41, 42, 43, and 45 have been removed and references were renumbered accordingly. The Table and references have been corrected as of 30 August 2010. The Table and references are correct in the printed version of the journal.

\footnotetext{
*carme.rodriguez@usal.es; Present address: Centro de Láseres Pulsados Ultracortos Ultraintensos, 37008 Salamanca, Spain.

${ }^{\dagger}$ Present address: Universidade de Vigo, 36310 Vigo, Spain.

${ }^{\ddagger}$ Present address: Centre d'Études Nucléaires de Bordeaux Gradignan, 33175 Gradignan, France.
} 